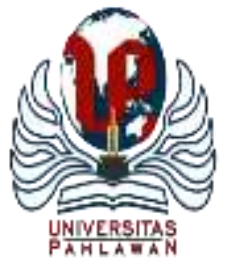

Edukatif : Jurnal Ilmu Pendidikan Volume 3 Nomor 6 Tahun 2021 Halm 4400 - 4406 EDUKATIF: JURNAL ILMU PENDIDIKAN

Research \& Learning in Education https:/ledukatif.org/index.php/edukatif/index

\title{
Analisis Pelaksanaan Pembelajaran Tatap Muka Terbatas (TMT) di masa New Normal terhadap Hasil Belajar Matematika di Sekolah Dasar
}

\author{
Mitra kasih La Ode Onde ${ }^{1 凶}$, Hijrawatil Aswat ${ }^{2}$,Eka Rosmitha Sari ${ }^{3}$, Nur Meliza ${ }^{4}$ \\ Universitas Muhammadiyah Buton, Indonesia ${ }^{1,2,3,4}$ \\ E-mail : mitralaodeonde@gmail.com ${ }^{1}, \underline{\text { hijrawatil171208@gmail.com }}{ }^{2}, \underline{\text { ekarosmita@gmail.com }}{ }^{3}$, \\ melizanur@gmail.com ${ }^{4}$
}

\begin{abstract}
Abstrak
Pelaksanaan pembelajaran tatap muka terbatas diseluruh satuan Pendidikan dibuka sejak juli 2021 melalui keputusan Menteri Pendidikan dan kebudayaan, Menteri Kesehatan, Menteri agama, dan Menteri dalam negeri terkait panduan penyelenggaraan tatap muka dimasa pandemic covid-19. Dua hal yang mendasari pelaksanaan pembelajaran tatap muka ini karena seluruh tenaga kependidikan telah divaksinasi dan selama pembelajaran jarak jauh atau daring, kualitas pendidikan mengalami penurunan dan tertinggal jauh dengan negara-negara lainnya selama masa pandemi. Sehingga penelitian ini bermaksud untuk menganalisi pelaksanaan pembelajaran tatap muka terbatas terhadap hasil belajar matematika siswa, tujuannya untuk mengetahui seberapa efektif pelaksanaan pembelajaran tatap muka terbatas terhadap hasil belajar matematika siswa, mengingat selama pembelajaran jarak jauh, muatan materi matematika yang paling mengalami kesulitan bagi guru dalam mengajarkannya. Sehingga melalui penelitian ini, memberikan gambaran pelaksanaan tatap muka terbatas dan strategi guru dalam menuntaskan capaian tujuan pembelajaran ditengah keterbatasan waktu belajar secara tatap muka. Metode penelitian ini menggunakan penelitian kualitatif, subjek penelitian ini ialah siswa kelas IV SDN 71 Buton yang berjumlah 14 siswa. Instrument penelitian yang digunakan menggunakan observasi lapangan, wawancara, tes, dan catatan lapangan. Hasil penelitian ini menunjukkan bahwa Pelaksanaan pembelajaran tatap muka terbatas dilaksanakan secara sistematis dan mengikuti panduan pelaksanaan PTM terbatas dimasa New Normal. Pihak sekolah telah merencanakan dan melaksanakan sesuai dengan prosedur protokol kesehatan, namun dari segi pelaksanaan proses belajar mengajar di kelas, penyampaian materi cukup dipadatkan dan hanya menyampaikan poin-poin pentingnya saja dan mempertegas pada penyelesaian latihan soal, sehingga siswa dipacu oleh waktu dan memaksimalkan waktu yang tersedia sehingga harus fokus dalam mengikuti pembelajaran. Guru tidak memanfaatkan model pembelajaran yang interaktif dan tidak melibatkan media pembelajaran media inovatif yang mendukung penyampaian informas secara kongkrit kepada siswa, sehingga hal demikian berdampak pada aktivitas siswa dan juga perolehan hasil belajar matematika siswa yang berada pada kategori cukup.
\end{abstract}

Kata Kunci: Pembelajaran tatap muka terbatas, New normal, Hasil belajar matematika.

\begin{abstract}
The implementation of limited face-to-face learning in all education units has been opened since July 2021 through a decision from the Minister of Education and Culture, the Minister of Health, the Minister of Religion, and the Minister of Home Affairs regarding the guidelines for holding face-toface meetings during the COVID-19 pandemic. Two things underlie the implementation of face-to-face learning because all education personnel have been vaccinated and during distance or online learning, the quality of education has decreased and is far behind other countries during the pandemic. So this study intends to analyze the implementation of limited face-to-face learning on students' mathematics learning outcomes, the aim is to find out how effective the implementation of limited face-to-face learning is on students mathematics learning outcomes, considering that during distance learning, the content of mathematics material is the most difficult for teachers in teaching it. . so that through this research, it provides an overview of the limited face-to-face implementation and the teacher's strategy in completing the achievement of learning objectives in the midst of limited time for face-to-face learning. This research method uses qualitative research, the subject of this research is the fourth grade students of SDN 71 Buton totaling 14 students. The research instrument used was field observations, interviews, tests, and field notes. The results of this study indicate that the implementation of limited face-to-face learning is carried out systematically and follows the guidelines for implementing limited PTM in the New Normal. The school has planned and implemented it in accordance with the Health protocol procedure, but in terms of implementing the teaching and learning process in the classroom, the delivery of material is quite condensed and only conveys the important points and emphasizes the completion of practice questions, so that students are motivated by time and maximize the time spent. available so that they must focus on following the learning process. Teachers do not use interactive learning models and do not involve innovative media learning media that support the delivery of concrete information to students, so that this has an impact on student activities and also the acquisition of students' mathematics learning outcomes who are in the sufficient category.
\end{abstract}

Keywords: Limited face-to-face learning, New normal, Mathematics learning outcomes.

Copyright (c) 2021 Mitra kasih La Ode Onde, Hijrawatil Aswat, Eka Rosmitha Sari, Nur Meliza

$\triangle$ Corresponding author

Email : mitralaodeonde@gmail.com

DOI : https://doi.org/10.31004/edukatif.v3i6.1449

ISSN 2656-8063 (Media Cetak)

ISSN 2656-8071 (Media Online) 
4401 Analisis Pelaksanaan Pembelajaran Tatap Muka Terbatas (TMT) di masa New Normal terhadap Hasil Belajar Matematika di Sekolah Dasar - Mitra kasih La Ode Onde, Hijrawatil Aswat, Eka Rosmitha Sari, Nur Meliza

DOI: https://doi.org/10.31004/edukatif.v3i6.1449

\section{PENDAHULUAN}

Pendidikan di Indonesia selama masa pandemic covid-19, mengalami perubahan aktivitas belajar yang berbeda dimulai sejak awal maret 2020. Pembelajaran jarak jauh menjadi alternatif yang paling efektif diterapkan selama negara Indonesia dilanda wabah covid-19, guna memutus rantai penyebaran yang semakin massif. Kasus konfirmasi covid terus bertambah dan menghentikan laju segala sektor, baik dari segi perekonomian, Pendidikan, pariwisata, dan lain sebagainya. Lonjakan pasien positif covid terus terjadi dan kian meningkat, sehingga perlu adanya peran dan kiat terkait upaya penanggulangan dan memutus rantai penyebaran yang lebih meluas. Salah satunya dengan menerapkan pembelajaran jarak jauh, sehingga kegiatan belajar siswa dilakukan dari rumah masing-masing. (Aswat et al. 2021) Pembelajaran jarak jauh menjadi alternatif pemerintah, sehingga siswa diwajibkan belajar dari rumah dengan bimbingan orang tua dibawah koordinasi guru. Hal ini tentu tetap menjadi tanggungjawab guru dalam memantau perkembangan belajar siswanya baik secara kognitif, afektif, maupun psikomotoriknya. Hasil kajian (Basar et al. 2021) membuktikan bahwa pembelajaran jarak jauh (PJJ) di masa pandemi covid-19 ini menimbulkan berbagai tanggapan dan perubahan pada sistem belajar yang dapat mempengaruhi proses pemebelajaran serta tingkat perkembangan peserta didik dalam merespon materi yang disampaikan. (Habibah et al. 2020) mengemukakan bahwa untuk mengefektifkan proses pembelajaran yang dilakukan maka dapat memanfaatkan tekhnologi media pembelajaran yang berbentuk platform seperti Google classroom, E-learning, Youtube, WAG, Edmodo, Zoom, Googlemeet dan platform lainnya. Namun bukan berarti pelaksanaan pembelajaran jarak jauh terlaksana dengan baik, karena hambatan sarana dan prasarana yang kurang mendukung pemanfaatan tekhnologi dalam pembelajaran. Sebagai mana yang diungkapkan oleh Nakayama (Dewi 2020) bahwa dari semua literatur dalam e- learning mengindikasikan bahwa tidak semua peserta didik akan sukses dalam pembelajaran online. Ini dikarenakan faktor lingkungan belajar dan karakteristik peserta didik. Terutama mata pelajaran yang membutuhkan penjelasan secara mendetail dan langkah pemecahan masalah, salah satunya mata pelajaran matematika yang identik dengan rumus, tentu membutuhkan model pembelajaran khusus dan media pembelajaran yang mendukung penyampaian materi secara daring.

(Fadilla, Relawati, and Ratnaningsih 2021) dalam penelitiannya tentang problematika pembelajaran matematika daring dimasa pandemic covid-19, hasil penelitian ini menunjukkan bahwa problematika yang terjadi yaitu diantaranya peserta didik merasa sulit untuk memahami materi pembelajaran yang disampaikan oleh guru, siswa tidak merasa termotivasi untuk belajar, siswa tidak meguasai pembelajaran dengan baik. (Basa and Hudaidah 2021) Pembelajaran matematika yang kurang dalam melibatkan peserta didik untuk aktif akan menyebabkan peserta didik tidak dapat menggunakan secara optimal kemampuan matematikanya dalam menyelesaikan permasalahan matematika. Untuk itu pembelajaran matermatika sangat penting melibatkan media untuk mengembangkan pemahaman siswa, sehingga diperlukan perencanaan yang matang. Namun pembelajaran matematika yang dilaksanakan secara daring setelah masunya wabah Covid-19 membuat proses pengajaran sedikit terhambat karena terkendala dalam menjelaskan materi yang tidak bisa dijelaskan secara langsung. Pembatasan aktivitas belajar inilah yang membuat tingkat pemahaman siswa terhadap materinya mengalami penurunan, karena alternatif pelibatan media pembelajaran online mengalami hambatan diantaranya kurang siapnya guru dalam pemanfaatan media, akses jaringan yang kurang memadai, ketersediaan kuota, terbatasnya kepemilikan smartphone, kurangnya pendampingan orang tua siswa, dan kurangnya pengalaman dalam pengelolaan kelas berbasis online.

Permasalahan lainnyapun muncul selama pelaksanaan pembelajaran jarak jauh, sehingga kualitas pendidikan di Indonesia dinilai mengalami penurunan dibandingkan dengan negara-negara lainnya, selama pandemic covid-19. Untuk itu pemerintah mulai mengatur strategi agar pembelajaran dapat dilaksanakan secara tatap muka. sehingga muncullah kebijakan baru tentang pelaksanaan pembelajaran tatap muka terbatas 
4402 Analisis Pelaksanaan Pembelajaran Tatap Muka Terbatas (TMT) di masa New Normal terhadap Hasil Belajar Matematika di Sekolah Dasar - Mitra kasih La Ode Onde, Hijrawatil Aswat, Eka Rosmitha Sari, Nur Meliza

DOI: https://doi.org/10.31004/edukatif.v3i6.1449

yang dibuka mulai juli 2021 dengan ketentuan seluruh tenaga kependidikan telah melakukan vaksinasi dan pembelajaran dilakukan dengan membatasi jam pertemuan, serta penerapan protokol Kesehatan yang ketat. Sehingga dalam hal ini, siswa dibagi kedalam kelompok belajar atau dijadwal berdasarkan shift, dengan tujuan membatasi jumlah siswa dalam satu ruangan. (Pattanang, Limbong, and Tambunan 2021) Perencanaan pembelajaran tatap muka perlu memperhatikan beberapa hal yang dapat di lakukan sekolah anatara lain: 1) Melakukan vaksinasi kepada seluruh pendidik dan tenaga kependidikan yang ada di sekolah;2) Meningkatkan imun peserta didik,pendidik dan tenaga kependidikan; 3) Mempersiapkan sarana dan prasarana yang sesuai protokol kesehatan. Sebelum diterapkannya pembelajaran tatap muka terbatas, kemdikbud telah mensosialisasikan dan menerbitkan buku panduan pembelajaran masa pandemic. (Kemdikbud 2020) Peran tim pembelajaran, diantaranya 1) melakukan pembagian kelompok belajar dan pengaturan jadwal pelajaran untuk setiap kelompok; 2) melakukan pengaturan tata letak ruangan; 3) memberikan batas pemisah dan penanda arah jalur koridor dan tangga; 4) menerapkan mekanisme pencegahan perundungan bagi warga satuan pendidikan yang terstigma covid-19; 5) menyiapkan seluruh peralatan penerapan protokol kesehatan.

Pelaksanaan tatap muka ini menerapkan prinsip kehati-hatian karena berkaitan dengan kesehatan dan keselamatan warga sekolah, sehingga protokol Kesehatan wajib diterapkan secara ketat sesuai dengan aturan pelaksanaan tatap muka terbatas. Pembelajaran tatap muka terbatas merupakan pembatasan jumlah peserta didik dalam satu kelas, sehingga perlu mengatur jumlah dengan system rotasi dan kapasitas $50 \%$ dari jumlah siswa pada normalnya, persetujuan orang tua siswa, penerapan protokol Kesehatan yang ketat, tenaga kependidikan telah melakukan vaksinasi, serta sarana dan prasaran pendukung pelaksanaan protokol Kesehatan tersedia.

PTM terbatas berlangsung selama 3 jam pelajaran untuk 1 shift, dan mengombinasikan dengan PJJ, sehingga PTM dilaksanakan 2 sampai 3 kali dalam 1 minggu. Setiap siswa melakukan PTM sebanyak 6 sampai 9 jam dengan sistem masuk dibuat selang seling dengan jeda beberapa menit, agar tidak terjadi penumpukan antara siswa yang akan pulan dan yang akan memasuki ruang kelas. Kondisi ini berdampak bagi guru dan siswa. Dampak bagi guru yaitu; 1) guru kesulitan mengelola pembelajaran dan cenderung focus pada penuntasan kurikulum, 2) waktu pembelajaran berkurang, sehingga guru tidak mungkin memenuhi beban jam mengajar. Sedangkan dampak bagi siswa yaitu; 1) siswa mengalami pengurangan interaksi sosial dengan teman-temannya, 2) mengeluhkan beratnya penugasan dari guru. 3) peningkatan rasa stress dan jenuh karena pembatasan aktivitas selama berada di sekolah, 4) pembelajaran didominasi oleh guru karena penyampaian materi yang cukup padat. Penelitian (Nissa and Haryanto 2020) menemukan fakta bahwa Guru menghadapi beberapa masalah yang dialamai diantaranya: keterbatasan waktu pembelajaran, dan teknis pelaksanaan pembelajaran yang masih rancu. Namun dengan demikian, kegiatan belajar sudah melibatkan interaksi langsung antara siswa dan guru secara tatap muka dan selebihnya dilakukan secara daring. Dengan demikian, penelitian ini bermaksud untuk menganalisis sejauh mana keberhasilan pelaksanaan pembelajaran tatap muka terbatas terhadap hasil belajar matematika siswa, sehingga memperoleh gambaran untuk dapat dijadikan sebagai rujukan dan bahan perbaikan selanjutnya bagi sekolah selama adaptasi PTM terbatas.

\section{METODE PENELITIAN}

Penelitian ini merupakan penelitian kualitatif, Miles dan Huberman 1992 (Rijali 2019) menggambarkan proses analisis data penelitian kualitatif sebagai berikut: 


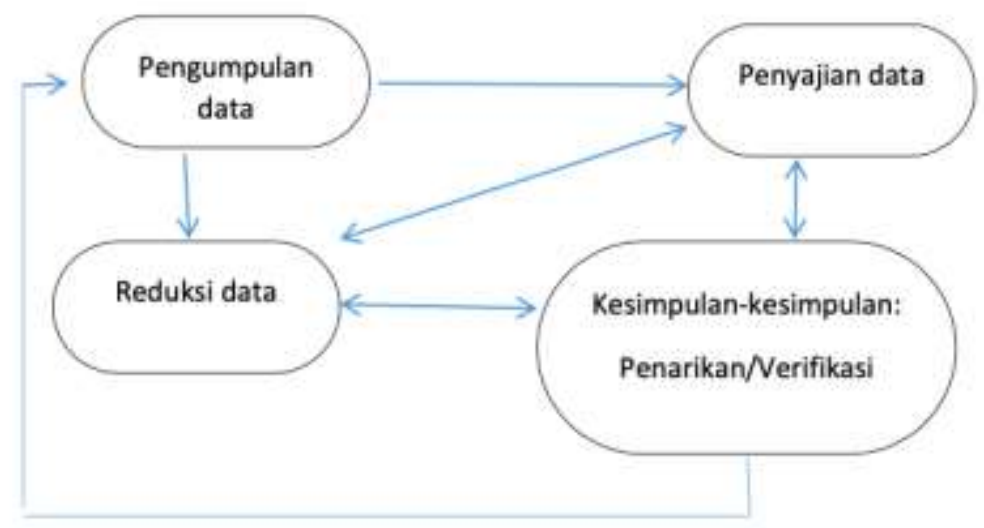

Gambar 1 Proses Analisis Data Penelitian Kualitatif

Penelitian ini dilaksanakan pada bulan juli sampai agustus 2021, yang bertujuan untuk menganalisis pelaksanaan pembelajaran tatap muka terbatas terhadap hasil belajar matematika siswa. Pada penelitian ini, data dan sumber data diambil dari siswa kelas IV SD Negeri 71 Buton tahun ajaran 2020/2021 berjumlah 14 siswa. Tekhnik pengumpulan data menggunakan lembar observasi kegiatan pembelajaran tatap muka terbatas, lembar observasi aktivitas belajar siswa, wawancara, tes, dan catatan lapangan.lembar observasi PTM diperuntukkan untuk mengumpulkan data pelaksanaan PTM dengan mengacu pada langkah kegiatan aktivitas guru selama proses pembelajaran. Lembar observasi siswa digunakan untuk melihat aktivitas atau respon siswa selama kegiatan PTM. Tes digunakan untuk melihat sejauh mana keberhasilan kegiatan belajar dengan melihat hasil belajar siswa melalui tes uraian. Wawancara dan catatan lapangan digunakan untuk memperoleh informasi tambahan lainnya seputar hambatan pelaksanaan PTM terbatas. Analisis data kualitatif dengan cara reduksi data, data display (penyajian data), dan conclusion drawing/verification (penarikan kesimpulan dan verivikasi).

\section{HASIL DAN PEMBAHASAN PENELITIAN}

Gambaran pelaksanaan pembelajaran tatap muta terbatas di SD Negeri 71 Buton khususnya pada siswa kelas IV, dilaksanakan sesuaikan dengan ketentuan pelaksanaan PTM terbatas. Sistem pembelajaran yang dilakukan memperhatikan protokol kesehatan dan merumuskan rencana kegiatan pembelajaran serta sarana prasaran pendukung pelaksanaan pembelajaran. Adapun tahapan pelaksanaan PTM terbatas sebagai berikut; 1) Perencanaan, pada tahap ini guru membagi siswa kedalam kelompok belajar yang terbagi menjadi dua kelompok belajar yakni kelompok A dan B yang masing-masing berjumlah 7 siswa, selanjutnya membuat jadwal pelajaran untuk masing-masing kelompok dengan ketentuan 3 kali pertemuan dalam satu minggu dengan pola masuk siswa ke kelas diatur dengan model shift, Mengatur tata letak bangku kelas dengan menjaga jarak aman tempat duduk siswa, memodifikasi materi pelajaran dengan mengkaji ulang beban ketuntasan materi dalam kurikulum untuk menyesuaikan dengan alokasi waktu 3 jam pelajaran untuk 1 kali pertemuan, mempersiapkan segala kelengkapan protokol kesehatan mulai dari alat pengecek suhu tubuh, handsanitizer, disinfektan, masker, alat cuci tangan dan sabun, memastikan peran orang tua siswa dalam memenuhi asupan gizi anak untuk menjaga imunitas tubuh anak; 2) Pelaksanaan, pada tahap ini sebelum memasuki lingkungan sekolah, maka wajib dipastikan seluruh warga sekolah memakai masker kesehatan, pengecekan suhu tubuh, mencuci tangan menggunakan sabun dan air mengalir yang telah disediakan sebelum memasuki ruang kelas dan setelah meninggal ruang kelas, siswa memasuki ruang kelas secara teratur dan menjaga jarak, seluruh siswa dipastikan memasuki ruang kelas dan menduduki bangku yang telah disediakan, 
4404 Analisis Pelaksanaan Pembelajaran Tatap Muka Terbatas (TMT) di masa New Normal terhadap Hasil Belajar Matematika di Sekolah Dasar - Mitra kasih La Ode Onde, Hijrawatil Aswat, Eka Rosmitha Sari, Nur Meliza

DOI: https://doi.org/10.31004/edukatif.v3i6.1449

jam istrahat ditiadakan; kegiatan ektrakurikuler dan olahraga serta kegiatan lainnya yang memancing aktivitas fisik jarak dekat masih ditiadakan; budaya rutinitas sekolah seperti upacara, perayaan hari besar keagamaan, serta kegiatan pengembangan diri lainnya juga masih ditiadakan; 3) evaluasi, pada tahap ini ialah meninjau keterlaksanaan kegiatan PTM terbatas dan melakukan sosialisasi kepada siswa agar aktivitas 3M yakni memakai masker, mencuci tangan, dan menjaga jarak menjadi pembiasaan bagi warga sekolah, selain itu melakukan sosialisasi melalui pembuatan spanduk tertib protokol kesehatan dan memberi edukasi terkait tata cara penerapannya serta tata cara warga sekolah memasuki lingkungan sekolah, karena masih ada beberapa siswa yang belum terbiasa dan belum memakai standar pemakaian masker sehingga hambatan-hambatan yang dihadapi selama pelaksanaan PTM terbatas, dilakukan perbaikan dan peningkatan manajemen pengelolaan PTM terbatas dengan baik.

Kegiatan belajar mengajar dibagi menjadi dua shift, sehingga dalam 1 kelas dibagi menjadi dua kelompok belajar yang terdiri dari masing-masing 7 siswa. Jam pelajaran juga dikurangi 50\% menjadi 3 jam pelajaran dalam 1 kali pertemuan, masuk jam 07 pagi sampai jam 10:00, sehingga masing-masing siswa memperoleh jatah belajar tatap muka sebanyak 9 jam dalam 1 minggu, karena masing-masing kelompok belajar telah dijadwal mengikuti PTM terbatas sebanyak 3 kali dalam 1 minggu dengan sistem rolling. Kegiatan siswa di sekolah dikhususnya untuk aktivitas belajarnya sehingga tidak ada aktivitas bermain, begitupun pada materi pelajaran yang diterima siswa cukup dipadatkan dan dipertegas pada penugasan yang dikerjakan siswa di rumah masing-masing. Selama proses pembelajaran, dipastikan aktivitas siswa aman, terkendai, dan tetap menjaga jarak. Dalam kegiatan belajar, kegiatan mengajar guru terlaksana cukup baik yang dimulai dengan kegiatan pendahuluan dengan menekankan pada pemberian motivasi belajar dan penguatan literasi, agar siswa dapat mengendalikan diri dalam menghadapi pandemi. Selanjutnya pada kegiatan inti, guru menyampaikan materi pelajaran khususnya mata pelajaran matematika dengan menyampaikan dasar-dasar atau point penting dari materi tersebut, memperbanyak latihan dan pengerjaan contoh-contoh soal, serta penugasan yang dapat dikerjakan secara mandiri dari rumah masing-masing. Kegiatan akhir atau penutup dengan memebrikan lembar kerja siswa sebagai bahan evaluasi dan pemberian tindak lanjut secara daring. Meskipun PTM terbatas telah dilaksanakan namun guru tetap menerapkan sistem pembelajaran daring karena keterbatasan jam pelajaran di sekolah mengakibatkan penyampaian materi pelajaran dianggap kurang optimal.

Aktivitas siswa dalam kegaiatan PTM terbatas, belum mampu memenuhi butir observasi aktivitas siswa diantaranya dalam bertanya, menemukan gagasan, mempertanyakan gagasan orang lain, belajar memahami, belajar dengan giat, menguasai pembelajaran, murid lebih bersungguh- sungguh dalam kegiatan belajar, murid menggunakan waktu sebaik- baiknya ketika belajar, berani bertanya, berani mengemukakan pendapat, dan berani memecahkan masalah. Terlihat masing-masing kelompok belajar hanya beberapa siswa saja yang terlibat aktif dalam aktivitas kelas, hal demikian terjadi karena pemecahan kelas menjadi dua kelompok berdasarkan karakteristik siswa dan kelompok yang heterogen sehingga kelompok dalam 1 kelompok belajar, ada siswa yang dianggap memiliki kemampuan lebih khususnya pada mata pelajaran matematika untuk menyeimbangkan kelas dan menghindari kelas yang pasif. Namun berdasarkan hasil observasi di lapangan saat pelaksanaan PTM terbatas pada mata pelajaran matematika, lebih difokuskan pada Latihan-latihan menyelesaikan soal matematika tanpa pelibatan model pembelajaran interaktif amupun media pembelajaran inovatif.

Setelah mengamati aktivitas siswa selama kegiatan pembelajaran, diakhir kegiatan diberikan tes uraian untuk melihat hasil belajar siswa sebagai bukti usaha yang telah dicapai. Adapun hasil belajar siswa kelas IV shift A dan B yang peneliti lakukan selama penelitian yang dilihat dari tes uraian yang berjumlah 10 tes dengan setiap soal memiliki bobot nilai 10, ditunjukkan pada tabel berikut: 
4405 Analisis Pelaksanaan Pembelajaran Tatap Muka Terbatas (TMT) di masa New Normal terhadap Hasil Belajar Matematika di Sekolah Dasar - Mitra kasih La Ode Onde, Hijrawatil Aswat, Eka Rosmitha Sari, Nur Meliza

DOI: https://doi.org/10.31004/edukatif.v3i6.1449

Tabel 1 Hasil belajar matematika siswa kelas IV

\begin{tabular}{|c|c|c|c|c|c|c|c|}
\hline No & Siswa & $\begin{array}{c}\text { Nilai } \\
\text { Shift A } \\
\end{array}$ & Tuntas & $\begin{array}{c}\text { Tidak } \\
\text { Tuntas } \\
\end{array}$ & $\begin{array}{c}\text { Nilai } \\
\text { Shift B }\end{array}$ & Tuntas & $\begin{array}{c}\text { Tidak } \\
\text { Tuntas } \\
\end{array}$ \\
\hline 1 & A & 80 & $\sqrt{ }$ & & 80 & $\sqrt{ }$ & \\
\hline 2 & B & 50 & & $\sqrt{ }$ & 90 & $\sqrt{ }$ & \\
\hline 3 & $\mathrm{C}$ & 70 & $\sqrt{ }$ & & 60 & & $\sqrt{ }$ \\
\hline 4 & $\mathrm{D}$ & 70 & $\sqrt{ }$ & & 40 & & $\sqrt{ }$ \\
\hline 5 & $\mathrm{E}$ & 30 & & $\sqrt{ }$ & 90 & $\sqrt{ }$ & \\
\hline 6 & $\mathrm{~F}$ & 80 & $\sqrt{ }$ & & 40 & & $\sqrt{ }$ \\
\hline 7 & G & 60 & & $\sqrt{ }$ & 80 & $\sqrt{ }$ & \\
\hline \multicolumn{4}{|c|}{ Nilai Rata-rata } & \multicolumn{4}{|c|}{65,71} \\
\hline \multicolumn{4}{|c|}{ Nilai Terendah } & \multicolumn{4}{|c|}{30} \\
\hline \multicolumn{4}{|c|}{ Nilai Tertinggi } & \multicolumn{4}{|c|}{90} \\
\hline \multicolumn{4}{|c|}{ Tuntas } & \multicolumn{4}{|c|}{8} \\
\hline \multicolumn{4}{|c|}{ Tidak Tuntas } & \multicolumn{4}{|c|}{6} \\
\hline & \multicolumn{3}{|c|}{ Ketuntasan Klasikal } & \multicolumn{4}{|c|}{$57,14 \%$} \\
\hline
\end{tabular}

Berdasarkan tabel 1, maka dapat disimpulkan bahwa perolehan hasil belajar siswa tidak memenuhi kriteria ketuntasan minimal secara klasikal yakni dikatakan suatu proses pembelajaran berhasil apabila siswa memperoleh hasil belajar yang mencapai KKM dengan standar nilai 65 untuk mata pelajaran matematika dan ketuntasan secara klasikal mencapi $80 \%$. Sementara data yang diperoleh dilapangan mengenai hasil belajar siswa diperoleh nilai rata-rata hasil belajar matematika 65,71 dengan ketuntasan belajar secara klasikal hanya $57,14 \%$ atau terhitung hanya ada 8 siswa yang tuntas hasil beajarnya dari 14 jumlah siswa dari dua kelompok belajar. Dengan demikian kategori hasil belajar matematika berada pada kategori cukup.

Pelaksanaan pembelajaran tatap muka terbatas dilaksanakan secara sistematis dan mengikuti panduan pelaksanaan PTM terbatas dimasa New Normal. Pihak sekolah telah merencanakan dan melaksanakan sesuai dengan prosedur protokol kesehatan, namun dari segi pelaksanaan proses belajar mengajar di kelas, penyampaian materi cukup dipadatkan dan hanya menyampaikan poin-poin pentingnya saja dan mempertegas pada penyelesaian latihan soal, sehingga siswa dipacu oleh waktu dan memaksimalkan waktu yang tersedia sehingga harus fokus dalam mengikuti pembelajaran. Guru tidak memanfaatkan model pembelajaran yang interaktif dan tidak melibatkan media pembelajaran media inovatif yang mendukung penyampaian informasi secara kongkrit kepada siswa, sehingga hal demikian berdampak pada aktivitas siswa dan juga perolehan hasil belajar matematika siswa yang berada pada kategori cukup.

\section{KESIMPULAN}

Berdasarkan observasi lapangan, wawancara, tes, dan catatan lapangan diperoleh informasi bahwa pelaksanaan PTM terbatas di SD Negeri 71 Buton terlaksana sesuai dengan panduan pelaksanaan PTM selama masa pandemi dengan penekanan pada penerapan protokol kesehatan yang ketat. Pelaksanaan PTM terbatas dilakukan dengan perencanaan yang matang, pelaksanaan yang cukup terarah, dan rutin melakukan evaluasi kegiaatan PTM dengan meminimalisir hambatan yang dialami selama kegiatan PTM terbatas berlangsung. Hasil belajar matematika yang tidak mencapai kriteria ketuntasan klasikal, dapat disimpulkan bahwa kegiatan belajar siswa dapat dikatakan tidak sukses memenuhi tujuan pembelajaran yang telah dirumuskan, hal demikian terjadi karena jam pelajaran yang kurang sehingga muatan materi cukup dipadatkan, sehingga pokok bahasan hanya membahas poin-poin pentingnya saja, selain itu kurangnya pemanfaatn media pembelajaran dan model pembelajaran interaktif yang dapat emmancing aktivitas belajar siswa dalam embgkonstruk pengetahuannya sendiri. 
4406 Analisis Pelaksanaan Pembelajaran Tatap Muka Terbatas (TMT) di masa New Normal terhadap Hasil Belajar Matematika di Sekolah Dasar - Mitra kasih La Ode Onde, Hijrawatil Aswat, Eka Rosmitha Sari, Nur Meliza

DOI: https://doi.org/10.31004/edukatif.v3i6.1449

\section{UCAPAN TERIMA KASIH}

Terimakasih kepada ibunda Rektor Universitas Muhammadiyah Buton yang sudah memberikan dukungan dalam penelitian ini. Kepada pihak penerbit yang sudah bersedia memeriksa artikel dan menerbitkan artikel ini. Terimakasih kepada banyak pihak yang sudah berkontribusi atas penyelesaian penelitian ini sampai menjadi artikel penelitian.

\section{DAFTAR RUJUKAN}

Aswat, Hijrawatil Et Al. 2021. "Implikasi Distance Learning Di Masa Pandemi COVID 19 Terhadap Kecerdasan Emosional Anak Di Sekolah Dasar.” Jurnal Basicedu 5(2): 761-71.

Basa, Zahra Alhumairah, And Hudaidah Hudaidah. 2021. "Perkembangan Pembelajaran Daring Terhadap Minat Belajar Matematika Siswa SMP Pada Masa Pandemi COVID-19." Edukatif: Jurnal Ilmu Pendidikan 3(3): 943-50. Https://Www.Edukatif.Org/Index.Php/Edukatif/Article/View/461.

Basar, Afip Miftahul Et Al. 2021. "Problematika Pembelajaran Jarak Jauh Pada Masa Pandemi Covid-19 ( Studi Kasus Di SMPIT Nurul Fajri - Cikarang Barat - Bekasi ) A . Pendahuluan Kemampuan, Sikap , Dan Bentuk-Bentuk Tingkah Laku Yang Bernilai Positif . Hal Itu Untuk Pencipta . Pendidikan S.” 2(1): $208-18$

Dewi, Wahyu Aji Fatma. 2020. "Dampak COVID-19 Terhadap Implementasi Pembelajaran Daring Di Sekolah Dasar." Edukatif: Jurnal Ilmu Pendidikan 2(1): 55-61.

Fadilla, Annisa Nurul, Ayu Suci Relawati, And Nani Ratnaningsih. 2021. "Jurnal Jendela Pendidikan." 01(02): 48-60.

Habibah, Riasatul Et A1. 2020. "Pemanfaatan Teknologi Media Pembelajaran Di Masa Pandemi Covid-19." Trapsila: Jurnal Pendidikan Dasar 2(02): 1.

Kemdikbud. 2020. "Panduan Penyelenggaraan Pembelajaran Di Masa Pandemi COVID-19." Kemendikbud 2019: 1-58. Https://Www.Kemdikbud.Go.Id/Main/Blog/2020/06/Buku-Saku-Panduan-Pembelajaran-DiMasa-Pandemi-Covid19.

Nissa, Siti Faizatun, And Akhmad Haryanto. 2020. "Implementasi Pembelajaran Tatap Muka Di Masa Pandemi Covid-19.” Jurnal IKA PGSD (Ikatan Alumni PGSD) UNARS 8(2): 402.

Pattanang, Emik, Mesta Limbong, And Witarsa Tambunan. 2021. "Perencanaan Pelaksanaan Pembelajaran Tatap Muka Di Masa Pandemi Pada Smk Kristen Tagari." Jurnal Manajemen Pendidikan 10(2): 112-20.

Rijali, Ahmad. 2019. “Analisis Data Kualitatif.” Alhadharah: Jurnal Ilmu Dakwah. 